\title{
Position change during colonoscopy improves caecal intubation rate, mucosal visibility, and adenoma detection in patients with suboptimal caecal preparation
}

\author{
Vijaypal Arya ${ }^{1,2}$, Shikha Singh ${ }^{1,3}$, Shashank Agarwal ${ }^{4}$, Ashok Valluri ${ }^{5}$, Oonagh Dowling ${ }^{6}$, Cristina Sison ${ }^{6}$, \\ Kalpana Arya Gupta ${ }^{2}$ \\ ${ }^{1}$ Department of Medicine, Hofstra Northwell School of Medicine, Hoftsra University, NY, USA \\ ${ }^{2}$ Department of Gastroenterology, Metrowell Health Center, NY, USA \\ ${ }^{3}$ Department of Internal Medicine, Wyckoff Heights Medical Center, NY, USA \\ ${ }^{4}$ Department of Internal Medicine, NYU Langone Health, NY, USA \\ ${ }^{5}$ Department of Medicine, Blessing Hospital, Quincy, Illinois, USA \\ ${ }^{6}$ Department of Biostatistics Unit, Feinstein Institute for Medical Research at Northwell Health, NY, USA
}

Gastroenterology Rev 2017; 12 (4): 296-302

DOI: https://doi.org/10.5114/pg.2017.72106

Key words: adenoma, caecum, colonoscopy, colonic neoplasms, colorectal cancer.

Address for correspondence: Vijaypal Arya, Department of Gastroenterology, Metrowell Health Center, 75-17 Metropolitan Avenue, 11379 Middle Village, United States, phone: +1 718326 0400, fax: +1 718326 0285, e-mail: varyamd@yahoo.com

\begin{abstract}
Introduction: Most colonoscopies are completed in the left lateral (LL) position but in cases of suboptimal caecal preparation, changing the patient's position to supine $(\mathrm{S})$ and, if needed, to right lateral $(\mathrm{RL})$ improves caecal intubation rate, mucosal visibility, and adenoma detection.

Aim: To determine if position change during colonoscopy facilitates optimal visualisation of the caecum.

Material and methods: A total of 359 patients were grouped into three categories based on the initial caecal intubation position. After caecal intubation, caecal visibility was scored on a four-point scale depending on the number of imaginary quadrants of the caecum completely visualized - Arya Caecal Prep Score. A score of 1 or 2 was unsatisfactory, while 3 or 4 was considered satisfactory. In patients with unsatisfactory score, position was changed from LL to $S$ and then RL and visibility was scored again.

Results: The initial caecal intubation in the LL position was achieved in $66.8 \%$ of patients, $S$ in $28.5 \%$, and RL in $4.8 \%$ of patients. 84.5\% (300/355) of patients had an acceptable visualisation score at the initial caecal intubation position. Of the 55 patients with unsatisfactory caecum visualisation scores in the initial intubation position, 30 (8.5\%) had satisfactory scores after the first position change (95\% Cl: 5.77-11.84). Twenty-five (7.04\%) subjects required two position changes (95\% Cl: $4.61-$ $10.22 \%)$. An additional 9.3\% (11/118) of adenomas were detected in caecum and ascending colon following position change.

Conclusions: Changing patient position improves caecal intubation rate, mucosal visibility, and adenoma detection.
\end{abstract}

\section{Introduction}

Colorectal cancer (CRC) is the second leading cause of cancer death in the United States, with both sexes having a $5 \%$ lifetime risk [1]. Colonoscopy is considered the gold standard for screening and surveillance of CRC, reducing incidence of CRC by $80 \%$ and mortality by $\sim 50 \%$ [2-4]. Adenomatous polyps are recognised as pre-cancerous lesions, and subjects with higher adenoma detection are at significantly higher risk of interval CRC $[5,6]$. Adenoma detection can be best achieved with good visualisation of colonic mucosa during colonoscopy. Factors found to improve colon visualisation and ADR include longer withdrawal time [7-9], retroscopy [10], the skill level of the endoscopist [11], level of fellowship training $[12,13]$, timing of the procedure $[14,15]$, chromoscopy $[16,17]$, bowel preparation quality [18], adequate colonic distension, position of the patient [19], and indication for the procedure.

Improvement in detection of right-sided colorectal cancer is imperative, given evidence that suggests colonoscopy is more protective for left-sided than 
right-sided cancer with colonoscopy [20, 21]. A population-based study by Bressler et al. estimated the miss rate as $4 \%$ in patients who underwent surgical resection for right-sided colorectal cancer [22]. During an incomplete colonoscopy, the right colon and caecum is less likely to be reached, in particular with less experienced endoscopists, leading to increased chances of missing a lesion. This failure to adequately visualise the caecal mucosa after intubation compromises lesion detection. Different measures to optimise the colonoscopy outcomes include suction (telescoping), wash/ suction, abdominal compression, position change [19], water immersion, shaft stiffening (Olympus), or via biopsy forceps and use of small diameter colonoscopes. In many instances, the caecal base is not completely seen secondary to prominent folds or faecal and vegetable matter obscuring the visibility. In $90 \%$ of cases the terminal ileum enters through the medial wall of the caecum, which is the dependent area in the left lateral (LL) position. It has been reported that while the patient is in the LL position, the medial wall of the caecum is dependent, and in most instances, the terminal ileum opens into this area [23]. When stool obscures this area, it becomes difficult to visualise the entire caecum. By changing the position of the patient, not only does the previously obscured area become visible but also not infrequently, the entire caecum is seen.

While some texts do recommend position change during colonoscope withdrawal to improve the luminal view, given the lack of empirical evidence, it has not become routine practice with colonoscopies routinely performed in the LL position for convenience [24]. Waye et al. found that abdominal pressure with or without position change facilitated performing complete colonoscopies more frequently [25]. Hasuda et al. reported an increased adenoma detection rate following position change or "posture conversion" in subjects undergoing a follow-up colonoscopy following a colonoscopy without position change [26]. A crossover study of 16 patients found that position change improved luminal distension score thus improving mucosal visibility with $43 \%$ of patients without position change having diagnostically unacceptable distention in one colon area [19]. In a follow-up study, East et al. reported improved adenoma and polyp detection with improved distention score following a sequence of patient position changes during colonoscope withdrawal in 130 patients [27].

\section{Aim}

With a greater emphasis on enhancing the diagnostic potential of colonoscopy, procedure-related techniques that could improve quality parameters need to be thoroughly evaluated. In this study, we determine whether change in position during colonoscopy results in improved visualisation of the caecum and therefore colonoscopy outcome.

\section{Material and methods}

The study was approved by the Institutional Review Board at Wyckoff Heights Medical Centre, and a waiver of informed consent was obtained. Patients aged 19 to 88 years who presented for colonoscopy for indications outlined in Table I, between November 2009 and February 2011, were invited to take part in the study.

\section{Colonoscopy}

Patients received midazolam and fentanyl for sedation. The endoscope used was a 160 PCF (Olympus Medical System Corp, Tokyo, Japan). A single experienced endoscopist performed all colonoscopies.

Table I. Demographics and baseline characteristics $(N=359)$

\begin{tabular}{|c|c|}
\hline Parameter & $N(\%)$ \\
\hline Incomplete exam & $4(1.1)$ \\
\hline \multicolumn{2}{|l|}{ Age, range [years] } \\
\hline $19-88$ & $359(100)$ \\
\hline $19-35$ & $24(6.7)$ \\
\hline $36-50$ & $81(22.6)$ \\
\hline $51-65$ & $181(50.4)$ \\
\hline$>65$ & $73(20.3)$ \\
\hline \multicolumn{2}{|l|}{ Sex: } \\
\hline Female/male & $207(57.7) / 152(42.3)$ \\
\hline Male & $152(42.3)$ \\
\hline \multicolumn{2}{|l|}{ Indication: } \\
\hline Screening: & $188(52.4)$ \\
\hline Average risk & $161(85.6)$ \\
\hline Prior polyp & 19 (10.1) \\
\hline Family $\mathrm{H} / \mathrm{O}$ of CRC & $4(2.1)$ \\
\hline Other & $4(2.1)$ \\
\hline Haematochezia & $48(13.4)$ \\
\hline Anaemia & $26(7.2)$ \\
\hline Constipation & 38 (10.6) \\
\hline Diarrhoea & $15(4.2)$ \\
\hline Abdominal pain & $13(9.5)$ \\
\hline Other & $10(2.9)$ \\
\hline
\end{tabular}


Table II. Quality of bowel preparation and caecum visualisation score characteristics

\begin{tabular}{|c|c|c|}
\hline Characteristic & Value & $95 \% \mathrm{Cl}$ \\
\hline Overall bowel prep quality: & $N=355$ & \\
\hline Poor & $14.08 \%(50 / 355)$ & $10.64-18.14$ \\
\hline Fair & $29.86 \%(16 / 355)$ & $25.14-34.91$ \\
\hline Good & $45.35 \%(161 / 355)$ & $40.09-50.69$ \\
\hline Excellent & $10.70 \%(38 / 355)$ & $7.69-14.40$ \\
\hline \multicolumn{3}{|l|}{$\begin{array}{l}\text { Initial caecum intubation } \\
\text { position: }\end{array}$} \\
\hline Left lateral & $66.76 \%(237 / 355)$ & 61.59-71.64 \\
\hline Supine & $28.45 \%(101 / 355)$ & $23.81-33.45$ \\
\hline Right lateral & $4.79 \%(17 / 355)$ & $2.81-7.56$ \\
\hline \multicolumn{3}{|l|}{$\begin{array}{l}\text { Caecum Visualisation } \\
\text { Score (at initial intubation } \\
\text { position): }\end{array}$} \\
\hline Poor & $4.79 \%(17 / 355)$ & $2.81-7.56$ \\
\hline Fair & $6.76 \%(24 / 355)$ & $4.38-9.89$ \\
\hline Good & $21.97 \%(78 / 355)$ & $17.77-26.64$ \\
\hline Excellent & $66.48 \%(236 / 355)$ & $61.31-71.37$ \\
\hline $\begin{array}{l}\text { Caecum visualisation } \\
\text { score (at initial intubation } \\
\text { position LL): }\end{array}$ & $N=237$ & \\
\hline Poor & $5.91 \%(14 / 237)$ & $2.17-6.53$ \\
\hline Fair & $6.33 \%(15 / 237)$ & $2.38-6.87$ \\
\hline Good & $23.63 \%(56 / 237)$ & 12.14-19.99 \\
\hline Excellent & $64.14 \%(152 / 237)$ & $37.61-48.15$ \\
\hline $\begin{array}{l}\text { Caecum visualisation } \\
\text { score (at initial intubation } \\
\text { position S): }\end{array}$ & $N=101$ & \\
\hline Poor & $2.97 \%(3 / 101)$ & $0.17-2.45$ \\
\hline Fair & $7.92 \%(8 / 101)$ & $0.98-4.39$ \\
\hline Good & $19.80 \%(20 / 101)$ & $3.47-8.57$ \\
\hline Excellent & $69.31 \%(70 / 101)$ & $15.71-24.24$ \\
\hline $\begin{array}{l}\text { Caecum visualisation } \\
\text { score (at initial intubation } \\
\text { position } \mathrm{RL} \text { ): }\end{array}$ & $N=17$ & \\
\hline Poor & $0 \%(0 / 17)$ & $0.00-0.84$ \\
\hline Fair & $5.88 \%(1 / 17)$ & $0.01-1.56$ \\
\hline Good & $11.76 \%(2 / 17)$ & $0.07-2.02$ \\
\hline Excellent & $82.35 \%(14 / 17)$ & $2.17-6.53$ \\
\hline
\end{tabular}

Colonoscopy preparation consisted of one-gallon polyethylene glycol based colon preparation, NuLytely (Braintree Laboratories Inc.), which had to be started at 4:00 pm the day before the procedure.

\section{Position changes of patient during colonoscopy procedure}

During colonoscopy, if the caecal intubation was not achieved in the LL position, then position was changed to intubate the caecum in the supine (S) and, if needed, the right lateral $(\mathrm{RL})$ position. The first position at which the scope initially reached the caecum was recorded and referred to as the initial caecum intubation position. After caecal intubation, patient position change was performed to improve the mucosal visibility and lesion detection rate of caecum as outlined (Figure 1). The performed patient position changes considered in this study were LL, S, and RL. The order of the patient position change was determined by the position of caecal intubation (Tables II, III). Once the caecum was intubated after confirmation by the anatomical landmarks, the visibility of the caecum was scored on a four-point scale depending on the number of imaginary quadrants of the caecum completely visualised - ACPS. If one quadrant was visible a score of 1 was given; if 2 quadrants were visible a score of 2 was given; if 3 quadrants were visible a score of 3 was given; and if four quadrants were visible a score of 4 was given. A score of 1 or 2 was considered unsatisfactory, while 3 or 4 was considered satisfactory. The position changes were only performed if the endoscopist gave a score

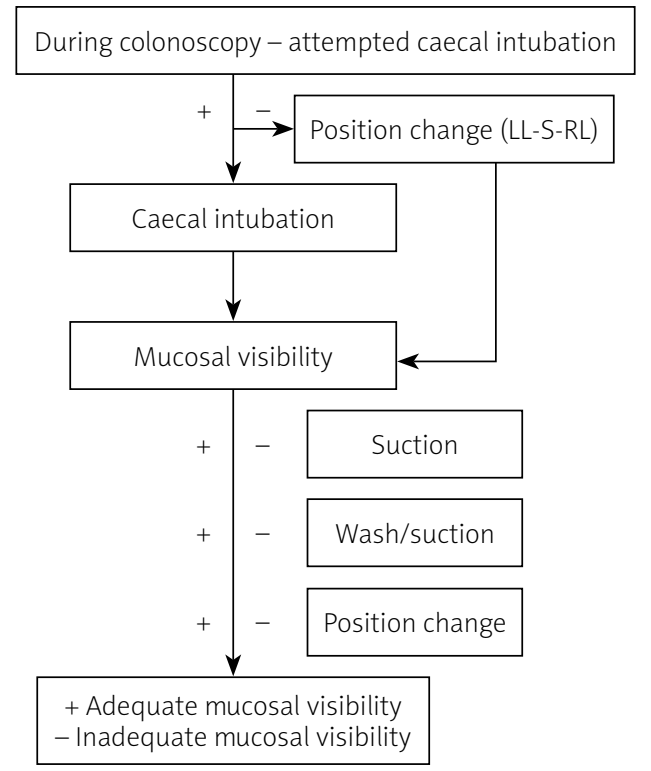

Figure 1 . Scheme used to visualise the mucosa of the caecum 
of 1 or 2 at the initial position of intubation. The scoring system was detailed as follows: entire caecum was divided into four imaginary quadrants and the lowest score of a particular quarter was given as the overall score after performing washing and suction: 1 - One of the four mucosal quarters with clear mucosal visibility; 2 - Two of the four mucosal quarters with clear mucosal visibility; 3 - Three of the four mucosal quarters with clear mucosal visibility; and 4 - All four mucosal quarters with clear mucosal visibility. The patient's position was changed during the procedure with the help of an assistant until the endoscopist viewed the caecal mucosa and had the best possible mucosal visibility (close to a score of 4). In each position, the mucosal visibility was evaluated using the same scale as described above.

\section{Statistical analysis}

The statistical analysis approach employed was primarily descriptive. Descriptive statistics such as means, medians, and standard deviations (SDs) were calculated for continuous variables, and proportions were estimated for categorical data along with their corresponding exact $95 \%$ confidence intervals

\section{Results}

The objective of this study was to determine if changing a patient's position during their colonoscopy procedure resulted in improvement in the visualisation of all four quadrants of the caecum. This improvement was estimated by determining the visualisation score at the initial position of caecum intubation and the subsequent visualisation scores at each change in the position. The subsequent "change score" calculated as the difference in best caecum visualisation score achieved and the initial caecum visualisation score was determined. The overall quality of the colon preparation was also scored on a four-point scale: poor -1 , fair -2 , good -3 , and excellent -4 .

This present study involved 355 consecutive patients scheduled for colonoscopy. These patients used a polyethylene glycol (GoLytely, NuLytely, or HalfLytely) for bowel preparation purposes. The characteristics of patients who completed the trial are presented in Table I. Fifty-two per cent of patients were referred for screening colonoscopies, with the remainder referred for specific evaluations such as anaemia, constipation, diarrhoea, abdominal pain, and haematochezia. The majority of patients (67\%) were initially intubated in the LL position (Table II). Based on the endoscopist's ratings, the majority of subjects had a fair to good overall colon preparation quality $(75 \%$ or $267 / 355)$ with $14 \%$ and $11 \%$ having poor and excellent bowel preparation quality, respectively (Table II). At the ini-
Table III. Order of performed position changes

\begin{tabular}{lcc}
$\begin{array}{l}\text { Caecal intubation } \\
\text { position }\end{array}$ & Position change 1 & Position change 2 \\
\hline Left lateral & N/A & N/A \\
\hline Supine & $L L-S$ & N/A \\
\hline Right lateral & $L L-S$ & $S-R$
\end{tabular}

tial intubation $67 \%$ of patients had excellent caecum visualisation and $85 \%$ had an overall satisfactory caecum visualisation score, indicating no position change was necessary. A total of 55 subjects required position changes to ensure better caecum visualisation. Thirty (8.5\%) needed one position change in order to achieve adequate visualisation and 25 (7\%) required two position changes to reach an acceptable caecum visualisation score (Table IV). Within these two subgroups of subjects, three and two did not exhibit any change in their caecum visualisation scores (Table V). Of these five subjects with no improvement in the caecum mucosal visibility score, three had solid stool adherent to the mucosa, and changing the position never improved the visibility. For the remainder, patient-related and technical factors made attempts to change the patient position impossible.

With respect to the change in caecum visualisation score, in the majority of patients ( $86 \%$ ) no position change was necessary and therefore the change in cae-

Table IV. Number of position changes to achieve acceptable caecum visualisation score

\begin{tabular}{lcc}
$\begin{array}{l}\text { Total number of } \\
\text { position changes }\end{array}$ & $\boldsymbol{N}=\mathbf{3 5 5}$ & $\mathbf{9 5 \% \mathrm { Cl }}$ \\
\hline 0 & $84.51 \%(300 / 355)$ & $80.32-88.11$ \\
\hline 1 & $8.45 \%(30 / 355)$ & $5.77-11.84$ \\
\hline 2 & $7.04 \%(25 / 355)$ & $4.61-10.22$
\end{tabular}

Table V. Improvement in caecum visualisation scores according to position changes

\begin{tabular}{llc}
$\begin{array}{l}\text { Number of position } \\
\text { changes from initial } \\
\text { intubation position }\end{array}$ & $\mathbf{N}=355$ & $95 \% \mathrm{Cl}$ \\
\hline $\begin{array}{l}\text { Position change: } \\
\text { Improved score }\end{array}$ & $90.0 \%(27 / 30)$ & $73.47-97.89$ \\
\hline No improvement & $10.0 \%(3 / 30)$ & $2.11-26.53$ \\
\hline Position change: & & \\
\hline Improved score & $92.0 \%(23 / 25)$ & $73.97-99.02$ \\
\hline No improvement & $8.0 \%(2 / 25)$ & $0.98-26.03$
\end{tabular}


Table VI. Change in caecum visualisation scores

\begin{tabular}{lcc} 
Score change & $\boldsymbol{N}=\mathbf{3 5 5}$ & $\mathbf{9 5 \%} \mathrm{Cl}$ \\
\hline 0 unit & $85.92 \%(305 / 355)$ & $81.86-89.36$ \\
\hline 1 unit & $4.79 \%(17 / 355)$ & $2.81-7.56$ \\
\hline 2 units & $5.92 \%(21 / 355)$ & $3.70-8.90$ \\
\hline 3 units & $3.38 \%(12 / 355)$ & $1.76-5.83$
\end{tabular}

cum visualisation score was zero. In 17 of the subjects (4.79\%), the change in caecum score was 1 unit; in $21(5.9 \%)$ the change was 2 units, and in $12(3.4 \%)$ subjects the change was 3 units (Table VI). One hundred and eighteen adenomas were detected. Of these, 11 were detected following position change ( 2 in caecum and 8 in ascending colon). Although our aim was adenoma detection in caecum, the resulting improved caecum and ascending colon visualisation led to the subsequent detection of $9.3 \%$ of total adenomas detected in both of these areas (Table VII).
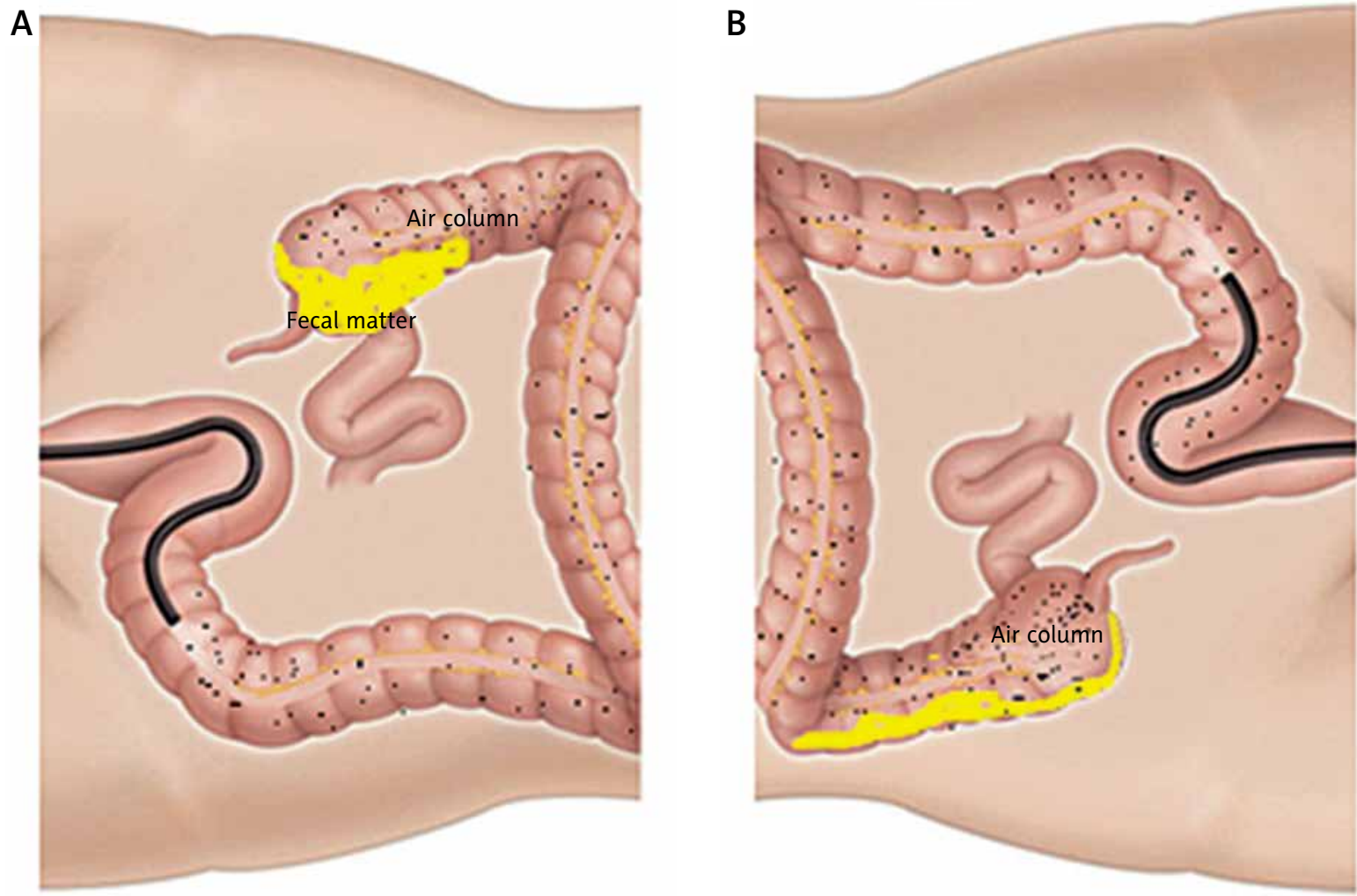

Figure 2. This figure implicate the possible mechanism of improved caecal visualisation with changing the position from left lateral (A) to right lateral (B). The formed faecal matter in the caput of caecum, which is the dependant part on the left lateral position of the patient, decreases the caecal visualisation. Changing the position to supine or right lateral moves the air column at the caecal base with the gravitational forces in action making the caput a non-dependant area, which results in the movement of the formed faecal matter from the caput of caecum 

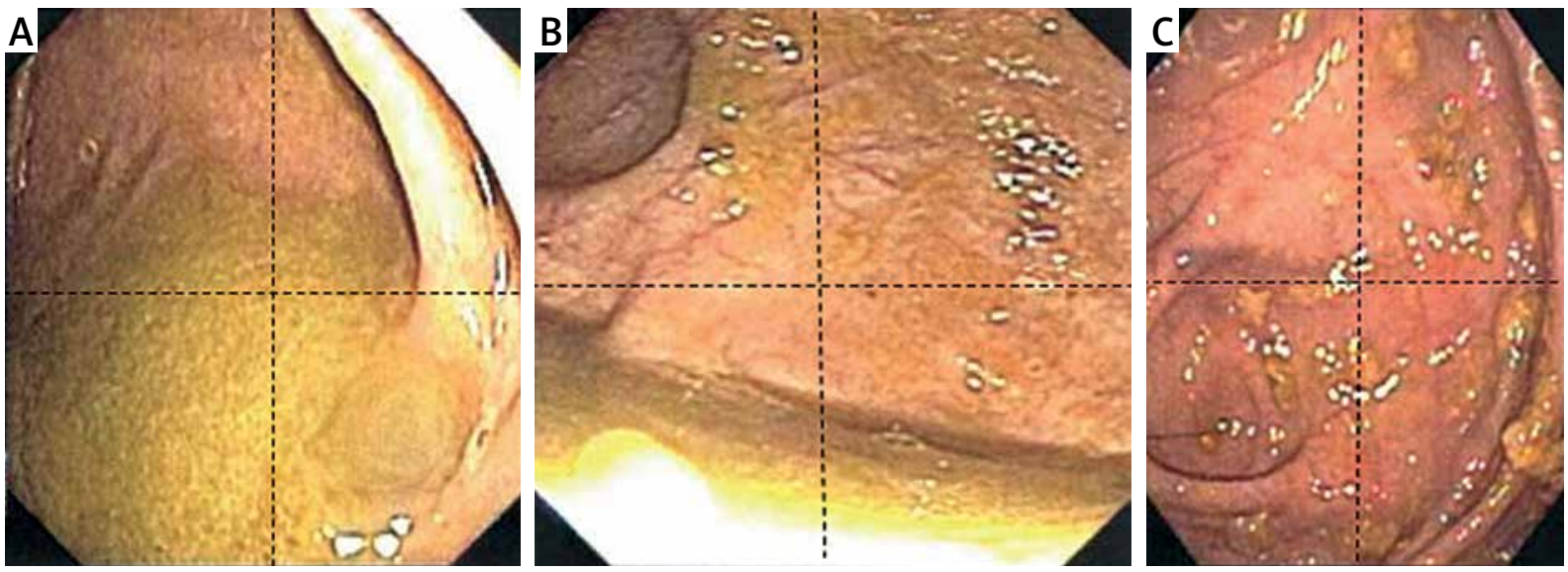

Figure 3. Image of the caecum in different positions showing change in ACPS (Arya Caecal Prep Scale) from left lateral position to right lateral position. A - In the left lateral position, mucosa of only 2 quadrants is satisfactorily visualised; therefore $A C P S_{L L}=2$. B - In the supine position, mucosa of only 3 quadrants is satisfactorily visualised; therefore $\mathrm{ACPS}_{\mathrm{s}}=3 . \mathrm{C}-$ In the right lateral position, mucosa of all 4 quadrants is satisfactorily visualised; therefore $\mathrm{ACPS}_{\mathrm{RL}}=4$

a cost-effective measure to improve outcomes including ADR [28].

The primary objective of this study was to determine if changing patient position during a colonoscopy procedure would result in improvements in visualisation of all four quadrants of the caecum. While position changes during colonoscope withdrawal have been recommended to improve the luminal view, the lack of empirical evidence has limited more widespread implementation of this technique. Our data demonstrate that while the majority of patients had initially satisfactory caecum visualisation, $15 \%$ required position changes. Of these $15 \%$, $8.5 \%$ required one change and $7 \%$ required two position changes to achieve adequate visualisation scores. One per cent of patients did not achieve adequate visualisation due to patient, technical-related factors or solid stool adherent to mucosa. Improvements in visualisation of caecum were translated into increased detection of adenomas, with $9.2 \%$ of total adenomas detected subsequent to position change. East et al. reported a mechanism that improved caecal visualization, adenoma and polyp detection rate with improved distention score following a sequence of patient position changes during colonoscope withdrawal. Other possible mechanisms include the shifting of fluid and debris away from the area being examined following position change (Figures 2, 3). Limitations to this study include it being a single-centre study and the colonoscopies being performed by a single endoscopist. It is also important that patients are not sedated deeply but should be awake enough to follow commands for position change. For younger generation gastroenterologists who are trained to do colonoscopies on very deeply sedated patients this could be a limitation. At the same time, patients who are not willing to feel any discomfort at all are not suitable for this intervention. Sedated patients have poor muscle tone and are prone to injuries i.e. shoulder or hip dislocation; hence, during position change extra care is warranted to prevent them. This can be done with the help of nursing staff and the anaesthesiologist.

\section{Conclusions}

Our results indicate that colonic visualisation and adenoma detection can be improved considerably through simple position change techniques with the majority of patients, with $92 \%$ of those requiring a position change achieving adequate visualisation. Ultimately, a trial involving a larger number of endoscopists is needed to validate the generalisability of our data and to determine whether improved visualisation mediated by position change leads to improvements in ADR and reduced colorectal cancer.

\section{Conflict of interest}

The authors declare no conflict of interest.

\section{References}

1. What are the key statistics about colorectal cancer? The American Cancer Society, 2015. [Online]. Available: http://www.cancer.org/cancer/colonandrectumcancer/detailedguide/colorectal-cancer-key-statistics. [Accessed: 11-Aug-2015].

2. Rex DK, Johnson DA, Anderson JC, et al. American College of Gastroenterology guidelines for colorectal cancer screening 2009 [corrected]. Am J Gastroenterol 2009; 104: 739-50.

3. Zauber AG, Winawer SJ, O'Brien MJ, et al. Colonoscopic polypectomy and long-term prevention of colorectal-cancer deaths. N Engl J Med 2012; 366: 687-96. 
4. Winawer SJ, Zauber AG, Ho MN, et al. Prevention of colorecta cancer by colonoscopic polypectomy. The National Polyp Study Workgroup. N Engl J Med 1993; 329; 1977-81.

5. Kaminski MF, Regula J, Kraszewska E, et al. Quality indicators for colonoscopy and the risk of interval cancer. $N$ Engl J Med 2010; 362; 1795-803.

6. Millan MS, Gross P, Manilich E, et al. Adenoma detection rate: the real indicator of quality in colonoscopy. Dis Colon Rectum 2008; 51: 1217-20.

7. Taber A, Romagnuolo J. Effect of simply recording colonoscopy withdrawal time on polyp and adenoma detection rates. Gas trointest Endosc 2010; 71: 782-6.

8. Gellad ZF, Weiss DG, Ahnen DJ, et al. Colonoscopy withdrawa time and risk of neoplasia at 5 years: results from VA Cooperative Studies Program 380. Am J Gastroenterol 2010; 105 : 1746-52.

9. Overholt BF, Brooks-Belli L, Grace M, et al. Withdrawal times and associated factors in colonoscopy: a quality assurance multicenter assessment. J Clin Gastroenterol 2010; 44: e80-6.

10. DeMarco DC, Odstrcil E, Lara LF, et al. Impact of experience with a retrograde-viewing device on adenoma detection rates and withdrawal times during colonoscopy: the Third Eye Retroscope study group. Gastrointest Endosc 2010; 71: 542-50.

11. Bretagne JF, Hamonic S, Piette C, et al. Variations between endoscopists in rates of detection of colorectal neoplasia and their impact on a regional screening program based on colonoscopy after fecal occult blood testing. Gastrointest Endosc 2010; 71: 335-41.

12. Peters SL, Hasan AG, Jacobson NB, et al. Level of fellowship training increases adenoma detection rates. Clin Gastroentero Hepatol 2010; 8: 439-42.

13. Rogart JN, Siddiqui UD, Jamidar PA, et al. Fellow involvement may increase adenoma detection rates during colonoscopy. Am J Gastroenterol 2008; 103: 2841-6.

14. Vicari J. The influence of timing of colonoscopy on adenoma detection: is timing everything? Am J Gastroenterol 2009; 104 1666-7.

15. Sanaka MR, Deepinder F, Thota PN, et al. Adenomas are detected more often in morning than in afternoon colonoscopy. Am J Gastroenterol 2009; 104: 1659-64.

16. Togashi K, Hewett DG, Radford-Smith GL, et al. The use of indigocarmine spray increases the colonoscopic detection rate of adenomas. J Gastroenterol 2009; 44: 826-33.

17. Hüneburg R, Lammert F, Rabe C, et al. Chromocolonoscopy detects more adenomas than white light colonoscopy or narrow band imaging colonoscopy in hereditary nonpolyposis colorectal cancer screening. Endoscopy 2009; 41: 316-22.

18. Deivert DE, Johal A, Kirchner HL, et al. Adenoma detection rates on screening colonoscopy in average risk patients at a large, rural tertiary care center. Gastrointest Endosc 2008; 67: AB315

19. East JE, Suzuki N, Arebi N, et al. Position changes improve visibility during colonoscope withdrawal: a randomized, blinded, crossover trial. Gastrointest Endosc 2007; 65: 263-9.

20. Rabeneck L, Davila JA, El-Serag HB. Is there a true 'shift' to the right colon in the incidence of colorectal cancer? Am J Gastroenterol 2003; 98: 1400-9.
21. Brenner H, Hoffmeister M, Arndt V, et al. Protection from rightand left-sided colorectal neoplasms after colonoscopy: population-based study. J Natl Cancer Inst 2010; 102: 89-95.

22. Bressler B, Paszat LF, Vinden C, et al. Colonoscopic miss rates for right-sided colon cancer: a population-based analysis. Gastroenterology 2004; 127: 452-6.

23. Jelbert A, Swinson S, Atkin K, et al. Imaging of the ileocaecal valve. Tech Coloproctol 2008; 12: 87-92.

24. Waye JD, Rex DK, Williams CB (eds.). Colonoscopy. Blackwell Publishing Ltd, Oxford, UK 2003.

25. Waye JD, Yessayan SA, Lewis BS, et al. The technique of abdominal pressure in total colonoscopy. Gastrointest Endosc 1991; 37: 147-51.

26. Hasuda K, Oda Y, Goto $\mathrm{H}$, et al. The improvement of finding neoplastic lesions in colonoscopy with posture conversion. Gastrointest Endosc 2005; 61: AB253.

27. East JE, Bassett P, Arebi N, et al. Dynamic patient position changes during colonoscope withdrawal increase adenoma detection: a randomized, crossover trial. Gastrointest Endosc 2011; 73: 456-63.

28. Köksal AŞ, Kalkan IH, Torun S, et al. A simple method to improve adenoma detection rate during colonoscopy: altering patient position. Can J Gastroenterol 2013; 27: 509-12.

Received: 30.03 .2016

Accepted: 18.11 .2016 